\title{
Gestures in the speech-language pathology clinic: a study in the light of the materialist discourse analysis
}

\author{
Michelle Fogaça de Oliveira Kitahara ${ }^{1}$ \\ https://orcid.org/0000-0001-6912-7585 \\ Regina Maria Ayres de Camargo Freire ${ }^{1}$ \\ https://orcid.org/0000-0002-6116-6165
} Pontifícia Universidade Católica de São
Paulo - PUC-SP, São Paulo, São Paulo,
Brasil.

Conflict of interests: Nonexistent

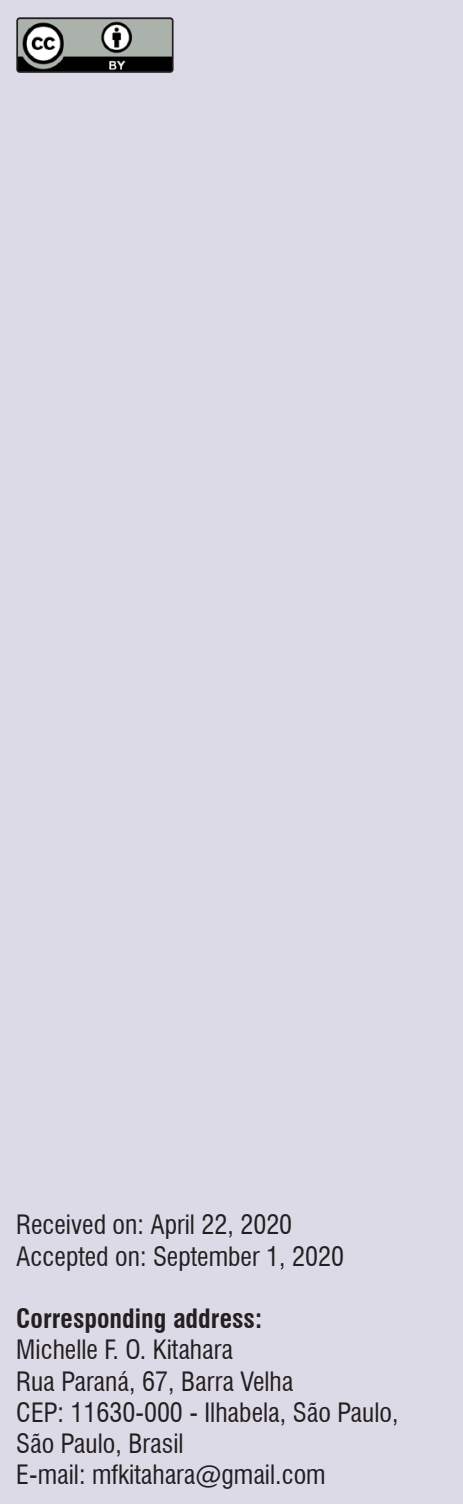

\section{Abstract}

Objective: this study aimed to investigate gestures in the speech-language pathology clinic and the dominant ideology in the light of the Materialist Discourse Analysis.

Methods: twelve speech-language pathologists who work in different clinical fields were interviewed to investigate the main discursive thread supporting their discourse. These semi-open interviews were recorded and the discursive data were later transcribed. Fragments were extracted and analyzed from the above mentioned perspective.

Results: the analysis shows that the conducting thread of the therapists' discourse is the positivist ideology of Science, which fragments the subjects, body and language allocating speech and gesture in a hierarchy system where gesture is subordinated to the former. The language materiality shows an unconscious identification of the therapists with the signifier "Fono-Speech, Audio-Audio, Logia-Study" (Fonoaudiologia, or Speech-language Pathology in Portuguese), since the return of speech and their professional identity is brought up. From this perspective, there are formations that challenge the dominant ideology welcoming gesture as an important tool in the clinic, both in evaluation and treatment.

Conclusion: the dominant ideological belief shows a hierarchical and historical association between speech and gesture that excludes gesture of the speech-language pathology clinic as it represents a threat to the speech status and the identity of this professional.

Keywords: Gesture; Address; Speech, Language and Hearing Sciences; Practice 


\section{INTRODUCTION}

The speech-language pathology clinic is characterized by a subject who has symptoms manifested by slips, stumbles in speech, repetitions, vocalizations, gestures and also silences. According to Freire ${ }^{1}$, although many of these manifestations are also observed in language development, the subject of the clinic has a demand for an enigmatic symptom that persists and causes suffering.

It is estimated that one in two hundred people is unable to communicate through speech due to neurological, physical, emotional and cognitive factors ${ }^{2}$. However, even aware of the value of speech to communication, language is present even when speech is affected $^{3}$.

The gesture produced in the speech-language pathology clinic in the therapist-patient relationship is seen in this study as a socio-historical process, which affects and is affected by the meanings produced from the interrelation of the semiotic systems of the subjects. Given the countless existing classifications, conceptualizing gestures is a tough task, which also faces difficulty with the wide and extensive use of this signifier that highlights different meanings, according to the most varied contexts and fields of those who are willing to study it. In addition to the manual gesture that includes the movement of the fingers, hands and arms, the orofacial gesture in the articulatory production of phonemes and the gesture of the hands in graphic production $^{4}$ are also mentioned in the literature; however, the latter two are not the focus of this study. The scientific basis for the definition of gesture is similar to the studies of McNeill5, one of the greatest scholars on the subject.

According to McNeill ${ }^{6}$, gestures are not just hand movements that rotate in the air without any meaning. Gestures are symbols that have meaning in their own way according to the person who produces them. Gestures can represent a character's hand, the whole character, the surface of a table, a ball or even a race car. The author also points out that the gesture has a meaning through the connection between speech and gesture and that, even though the language of the gesture is based on visual and mimetic images and speech is based on a grammatical structure and word codes, both combine in a unique and integrated system. In addition, he proposes a classification of gestures according to their semiotic differences, linguistic properties, convention and relationship with speech, according to the following examples:
- Gesticulation: when the person says that picked up a tree, he moves his hand forward and upwards in a "c" shape as a preparation to "grab" the imaginary tree. In this example, it is clear how much gesture and speech may have similar information on the same scene, but each can include some aspect that the other leaves behind.

- Pantomime: the person would be rotating his finger in a circle when asked "what is a vortex?";

- Emblematic: the OK gesture, which is culturally known to express approval with closed fingers and extended thumb up;

- Sign language gestures, as the tree sign that is made with the forearm extended above while the 5 flexed fingers rotate back and forth; the other arm is extended horizontally and below the other arm.

- Pointing gestures, also known as deictic gestures, are usually produced with the index finger extended or all fingers extended and are often used to replace speech when referencing something.

In fact, when people talk, they use gestures at all times, whether to emphasize specific words, sentences or to make a reference to size, shape, direction, distance, etc. ${ }^{7}$. Furthermore, gestures may have information that is not explicit in the speech and may replace the spoken word or happen concurrently with it ${ }^{8}$.

Therefore, the study of gestures is essential to understand the language and communication of people and, as well as oral language, it is a unique behavior of the human being that differs us from other animals in its complexity. Given their relative transparency in the relationship between form and function, gestures play an important role in communication. Still according to the author, most gestures are produced only in the presence of others, in significant situations of face-toface interaction involving eye contact.

From another perspective, Capone and McGregor ${ }^{9}$ emphasize that the gesture-speech-language synchrony occurs due to the neurological integration of these systems, and the activation of a particular brain region can affect the other and vice versa. This correlation between hand and mouth has been observed since birth, such as when the baby's hand is pressed and the baby tends to open his mouth or, when the baby makes rhythmic movements with his hands and the number of his vocalizations tends to increase. According to these authors, since gesture and language develop in parallel and share similar symbolic skills, the study of gestures may contribute to the understanding of language development in children 
with or without pathology, thus contributing to the assessment, diagnosis and intervention therapy.

The most recent scientific research continues to give due importance to the topic. Yu and Smith ${ }^{10}$ reported evidence on how adults and children are highly attentive to hand actions. According to the authors, some people believe that having a conversation or solving a problem together is something very simple and natural, but these interactions are characterized by imperceptible adjustments that take place in fractions of seconds, such as the direction of the look and hands. However, the direction of the look may be spatially less precise than the contact of the hand with an object. Therefore, both babies use their own hands to select visual objects, and parents use the manual actions of the babies to interpret and give meaning.

Goldin-Meadow and Alibabi ${ }^{11}$ stand out in this sense when they report that, even though often unnoticed, gestures are actually helping to produce speech.

Guedes $^{12}$ adds that gestures are often used when more complex cognitive processes are required, and they can also anticipate the expression of a word. In turn, the studies conducted by Rauscher ${ }^{13}$ show that people become more disfluent when the use of gestures is prohibited.

The results reported by Cook and Goldin-Meadow ${ }^{14}$ show that children benefit much more from instructions when they include gestures and that gestures facilitate learning when used concurrently with spoken language. In this sense, Iverson and Goldin-Meadow ${ }^{7}$ also stand out when they report that many meanings of visual-spatial representation may be easier to be expressed by gesture than by speech. These authors suggest that there are two main categories of gestures, namely, deictic and conventional gestures. Children are able to produce 3 types of deictic gestures: showing, holding a certain object in view of the other and pointing by extending the index finger or extending the hand towards a referent. Conventional gestures are those that have culturally defined form and meanings, such as shaking your head to say yes. Conventional gestures can also be specific gestures established on the dyad in a particular context, such as when touching your head in a specific interaction situation to say "beautiful".

Still in the clinical context, as in the case of aphasic patients, Fedosse ${ }^{15}$ understands that gestures may often replace or accompany verbal expression. In addition, gestures can also be expressed in a disorganized way as if there was also a syntactic disorganization of the gesture; in other cases, the gesture may not even be performed. According to Code and Gaunt ${ }^{16}$ gestures can be used as an alternative to speech, relieving pressure on those who have impairment in this aspect, as in the cases of aphasia and apraxia. Coudry ${ }^{17}$ reports the correlation between the greater use of gestures and the severity of the speech pathology, working as an important instrument for the patient to give meaning to what he wants.

In addition to the symbolic character and the importance of gestures in communication, Capone and Mcgregor ${ }^{9}$ emphasize that they can also be used to compensate or make the transition to speech development. In addition, gestures in the speech therapy clinic may be valuable sources of diagnosis and prognosis, helping in the selection of objectives and in the intervention of children with language difficulties.

In the context of care for people with Autism, given the high incidence in the diagnosis within the spectrum, screening questionnaires have been used by doctors and health professionals as a method for early identification of children with autism. The M-CHAT (Checklist for Autism in Toddlers) questionnaire is one of these instruments that has been translated into Portuguese ${ }^{18}$ and is currently used with relevance in Brazil. It should be noted that $13 \%$ of the questions of this checklist are related to pointing gestures (deictic gestures).

A similar work proposed by Muratori ${ }^{19}$ in Italy uses questions for pediatricians to explore the possibilities for a child to develop an autistic disorder in their first year of life. $23 \%$ of these questions are related to gestures, which indicates that they can be an important aspect to be observed also in speech-language pathology clinic, both in the evaluation and in the early diagnosis of children who are at risk for the autistic spectrum. Also, according to the aforementioned author, shared intentionality, which is a typically human attribute, is very fragile in children with autism and the gesture of indicating or pointing is the maximum expression, either of declarative motivation or in the intention to share experiences. The absence of this protodeclarative pointing in the second year of life is considered one of the most important signs of autism.

In addition to being considered one of the first expressions of the child with communicative intent and also an important method for assessment, prognosis and intervention, there are few Brazilian scientific researches that try to understand its specific role in speech-language pathology clinic. 
The possibilities of using the gesture as a complementary technique in speech-language pathology care also stand out. Therefore, this study aims to investigate the gesture in the speech-language pathology clinic in the light of the materialist discourse analysis. In this way, contributing to the expansion of the therapeutic possibilities of the speech-language pathologist and to the reflection of practices focused on gestures.

\section{Brief Historical Report}

In general, the study of gestures in recent years has shown a detachment from that meaning of the Roman tradition, in which it was seen only as an embellishment of the rhetorical performances of the speakers of that time. The first changes in this perspective began with the advent of technology, which made it possible to record videos and images in moments of conversation and in other types of discourse ${ }^{5}$. Still according to the same author, the second change occurred around the 1970s and prevails to this day, in which the gesture is understood as an integrated part of the language process and its use. Since then, different fields of study have focused on differentiated approaches and objectives, such as the transition from gesture from its form of gesticulation to the most coded of sign.

For Speech-Language Pathology, the use of gestures in their most codified form has an important historical mark in its clinical practice with deaf people, as in the case of the Brazilian Sign Language (BSL). In turn, sign language began to be studied and analyzed only from the 1960s, since only the oral language that could be understood by hearing had linguistic status until then ${ }^{20}$. Historically, for a long time, there was a controversial discussion as to which language modality should be used in the education of deaf people, especially if oral or visual. At the $2^{\text {nd }}$ International Congress on the Education of the Deaf in 1980, in Italy, the conference discussed oral-only education versus an education that utilizes sign language in schools, and this perspective influenced many countries at the time ${ }^{21}$.

The bilingual approach started to be discussed in Brazil only from $1990^{22}$. This approach moved from the clinical speech-language pathology model that emphasized only an articulatory and auditory work, towards a work that also used visual resources and dialectics, calling on this professional to include the constitutive singularity of the deaf within their clinical practice.

\section{Therapeutic Approaches}

Gestures, sign language, facial expressions, alphabet boards or pictographic symbols, and even the use of more sophisticated systems, such as recorded or synthesized voice communicators and computers, are considered forms of Alternative and Extended Communication ${ }^{23}$. Given their speech and/ or writing difficulties, many people with cerebral palsy, mental disability, hearing impairment, autism or multiple disabilities will need an alternative form of communication ${ }^{24}$.

Although many programs have been developed over the years with different purposes and bases, Scheet $z^{21}$ believes that most are based on the intention of making spoken language accessible to the deaf. According to the author, it is interesting to note that sign language is a complete language system with its own syntactic structure and vocabulary. Thus, it is a visual sign language that can develop naturally in deaf communities.

Thus, it is believed that many approaches have been increasingly used with people who also had speech difficulties for some reason. It is believed that the vast scientific production in the area in other countries, as well as the proximity of several professionals increasingly involved in the care and inclusion of people with a disability, may have influenced the development of educational an speech-language pathology practices, which understand the gesture as a bridge for the interaction and the development of speech and learning. Some strategies that use manual gestures as a therapeutic approach are: Cued Speech ${ }^{25}$; Cued Articulation ${ }^{26}$; Makaton ${ }^{27}$; Baby Signing ${ }^{28 ;}$ Prompting Gestual04; Tadoma ${ }^{29}$; SUVAG ${ }^{30}$; among others.

Therefore, this study aims to investigate the use of gestures in the speech-language pathology clinic through the speech analysis of the speech-language pathologist.

\section{METHODS}

This study was carried out based on the ethical principles that define the regulatory norms and guidelines for research involving human beings under the no. 67864217.0.0000.5482, from the Pontifícia Universidade Católica de São Paulo, SP, Brazil (05014-901). This is an exploratory and qualitative applied study. 


\section{Sample}

The research included 12 speech therapists with academic backgrounds and different specializations who agreed with the terms to participate in this study and who work in the therapy of the main fields of Speech-Language Pathology that may be associated with gestures, that is, oral and written language, voice and auditory rehabilitation. In order to obtain as much information as possible, professionals who do not work in the therapeutic area were excluded from this study, such as those whose practice is restricted to hearing tests or teaching.

\section{Site}

Data collection was carried out in a place established according to the interviewees' convenience, on prearranged dates and times. All interviews were conducted by only one researcher from October 2016 to April 2017.

\section{Procedures}

All sessions were recorded in audio and video. Data were collected and transcribed so that the therapists could access the materiality in the speech of the subjects.

The interview was intended for therapists to speak freely on the subject. To this end, the interviewer tried to start the interview with questions about their opinion on gestures and how it was used in their clinical practice. Therefore, the semi-structured interview aimed at giving therapists freedom to explore the subject and, thus, the questions asked by the interviewer varied and sought to integrate with their discourse, as suggested by Mattos $^{31}$. Also, according to the author, some questions were designed in order to clarify and better understand information, as well as to direct the interview to the proposed topic, when necessary.

\section{Discursive analysis}

The data were analyzed from the Materialist Discourse Analysis, which is based on the intersection of three new fields of knowledge, that is, linguistics, psychoanalysis and historical materialism. The methodology proposes an analysis of the gestures of interpretation, in addition to the linguistic code, considering the socio-historical influence in the process to constitute and understand the discourse.
This analysis is not intended to offer an exhaustiveness of the data like most studies. Orlandi ${ }^{32}$ suggests the verticality of the analysis, since the speeches are not closed, as they are always in motion through the discursive process. According to the author, the question of the researcher defines the shape of the analytical device, since it chooses to mobilize different concepts, in addition to the nature of the material and the purpose of its analysis. This analysis provides for 3 distinct stages that take place in the move from text to discourse, namely: from the linguistic surface to the discursive object and from there to the discursive process: $1^{\text {st }}$ Stage $=$ Linguistic Surface $($ Text $) ; 2^{\text {nd }}$ Stage $=$ Discursive Object (Discursive Formation); $3^{\text {rd }}$ Stage = Discursive Process (Ideological Formation).

Thus, the linguistic material is obtained as such in the first movement of the analysis, that is, the corpus or the texts that are intended to be analyzed. In the second stage, the surface of this material is crossed and the discursive formations that dominate the text are already being perceived. In the third stage, which is called discursive process, the analyst seeks to observe the relationship of the discursive object with the ideological formations ${ }^{33}$.

The discursive object constructed must be able to explain the subject's impressions of their own saying. This illusion of autonomy is reported by Pêcheux ${ }^{34}$ as forgetfulness number 2; that is, the forgetfulness of the subject when selecting in his enunciation process between what is said and what is not said, even if he does not know the existing interconnection between both; on the other hand, the forgetfulness number 1 is the analogy of unconscious repression, as the subject is not accessible to a discursive formation that already dominates him.

In the second stage, it is essential to work within the limits of the sliding movements of the axes of meaning between the tension of repetition and difference, paraphrase and polysemy ${ }^{32}$. The paraphrase becomes a space for closing borders, in which statements are resumed and reformulated, in contrast to polysemy, which is the breaking of these barriers as the plurality of meanings is established ${ }^{35}$.

According to Orlandi ${ }^{33}$, every subject uses a certain memory file that appears denied as if the meaning was already there. Thus, the functioning of a discourse and its relationship with the subject and ideology can also be understood by the effects of historical memory (interdiscourse) and metallic memory (computerization 
of files, which accumulates) and that, when structured by forgetfulness, produces an effect of control and illusion of authorship.

Brandão ${ }^{35}$ states that one of the most important contributions of Pêcheux, also to Speech-Language Pathology, is to allow looking at the protagonists of the discourse, not just to the physical presence of the individual, but as a representation of determined places in the class structure of our social formation. In this way, the procedure of analysis of the discursive process must consider the characteristics of the images that the subjects make of themselves and of the other in front of the different positions that they take in a given social group.

This place of social representation is called power relationship. In turn, anticipation concerns the strategy of putting oneself in the place of the other with the aim of predicting their sayings, also enabling the "control" of responses ${ }^{32}$. The same author reports that words are always accompanied by silences and by the power relations of class society and, therefore, there is a judgment of what is acceptable to say or not, or what can or cannot be said, producing a certain way of censorship. Such senses, which are sometimes produced and sometimes silenced, must also be taken into account by the analyst during the analysis.

In short, Lagazzij6 reports that this whole process involving discursive desyntagmatization, as well as the historical determination of the effects of meanings and their relationship with different ideological formations, is not a watertight process, since these formations are already associated in the first stage of the analysis. However, these ideological formations are interconnected by their own complex relationship with social formations, the so-called historical materialism.

\section{RESULTS}

In Portuguese, the word fonoaudiologia (speechlanguage pathology) is derived from 'FONO', from the Greek "phone", which means voice, sound; 'AUDIO' from Latin to hear; and 'LOGIA', which means study, science. The language in its authoritarianism meets the initial purpose of this study, that is, the questioning of the gesture in the speech-language pathology clinic that referred us to the speech status through the discourse analysis of the professional speech-language pathologist. The language in the etymology of the signifier "fono", of Fono-Audio-Logia, seems to force us to identify ourselves as the scholars of the articulation of speech sounds. Even so, especially in Brazil, this signifier is related to the prefix "audio", evidencing a relationship of implication between these two terms.

Even knowing that the etymological meaning of words does not represent the meaning of the full word, this effect was present in this case related to the results of this study. Language in its authoritarianism, in the case of Fono-audio-logia, silences other senses, silences language. Even though fragmentation is the basis of every scientific study, there are consequences when this reductionism is not included in relation to the whole, thus showing the effect of ideology on science.

The articulation of Linguistics, Psychoanalysis and Historical Materialism allowed an increase in the lenses of the speech-language pathology, where the focal adjustment was directed to the gesture as an effect of meanings in the relationships between therapist and patient, as well as in the therapeutic approaches of the speech-language pathology clinic.

There was an anchor point in the discourse of the speech-language pathology supported by a fragmented view of the subjects, similar to the incision in the Medicine, a science that has historically served as a foundation in the construction of speech-language pathology knowledge and practice. The ideological belief in the division of labor in society, where a particular more powerful class submits to another in the form of hierarchy and dependence, is also evidenced by having gesture as an object of discourse: "But orality is our greatest form of communication, so it is what we have most, it is the privilege of orality to the detriment of other forms of communication" (excerpt from the interview of S1); "Of course, as a professional of oral language... of course, I don't allow only the gesture" (excerpt from the interview of S2); "Otherwise you may say: Oh! You can communicate only with gestures..." (excerpt from the interview of S3); "I work for oral rehabilitation" (excerpt from the interview of S4); "Now that you came with these questions that we can see... communication is not just about speech" (excerpt from the interview of S5).

This ideology exposes the tension and consequences of the hierarchical division, in which the separation of society, subjects and bodies is also materialized in the separation of language. The discourse development in this work seems to be constituted from the speech as a point of return and support of the discourse. Is there then an anchor point in speech reductionism?

As a method and theory, the DA allowed us to observe "how" the movements of meanings are 
produced and "which" meanings are evidenced in this study. According to Orlandi ${ }^{32}$, the DA conceives the text in its semantic discourse and asks it to know "how" it means and not "what". At first, the discourse of the therapists in the form of interrogation showed a strangeness and doubt when having the gesture as object of reflection: "Gesture? What do you mean? ... I never thought about that." (excerpt from the interview of S5); "I guess it has a certain meaning there, right? You can't say it's hollow, right?" (excerpt from the interview of S3). The negatives also showed this strangeness: "Actually, I don't think about it much when I'm in my clinical practice... too bad that I don't have many examples in my head" (excerpt from the interview of S6); "I don't know, I think it appears a lot in this conversation ... I never really thought about it that much. I never thought so much about my gesture itself" (excerpt from the interview of S7); "I don't let him communicate with me through gestures" (excerpt from the interview of S2).

The strangeness and doubt showed by the speechlanguage pathologists expose the dominant ideology that, by silencing, erases the gesture of the speechlanguage pathologists, excluding this object from its field of knowledge. According to Orlandi ${ }^{33}$, to say, it is necessary not to say and, in this case, the reason for never thinking about something, as the gesture, is implied and must be understood by the context. Thus, it was found that the questioning about the gesture was also associated with the signifiers "deaf' and "BSL", implicitly referring to the historicity of this discourse. Hence, we have: "no, I don't use the BSL (excerpt from the interview of S4); "Gesture or sign? (excerpt from the interview of S3); "maybe if I worked with hearing impaired people, the gestures could appear" (excerpt from the interview of S2); "She came (deaf patient) and used it, but she doesn't want anyone in the world to know it" (excerpt from the interview of S5) and others.

The importance of understanding the idea of ideological forgetfulness evidences in its silencing the illusion of the subjects as owners of their sayings, when language and history are determining the produced meanings ${ }^{33}$. Throughout its history, speech-language pathology has spent a lot of time focused only on the articulatory aspects of speech correction, especially when working with the deaf community. It was only recently that it was allowed to question this performance, assuming a therapeutic approach also contemplating the use of signs and gestures, as reported by Pereira $^{37}$.
The excerpt "it was kind of a natural way for me, so I started my own way of working" (excerpt from the interview of S6) shows meanings that are similar to the speech of another therapist arising from the speech of teachers: "I think they used to see it as natural, nothing that deserved special attention, right? However, it could be something natural for the child, maybe it didn't need to be interpreted, and it didn't need to be stimulated, right?" (excerpt from the interview of S8). Starting again from the idea of historicity, the effects of the pedagogical discourse are also evident as a historical characteristic of the discourse of the speech-language pathology. In some moments, this professional is still rooted in the original pedagogical structures of speechlanguage pathology, whose focus was hygiene and speech correction in the incessant search for an ideal of normality. This hygiene and class society project was transformed into measures of control and authoritarianism, where the role of the speech-language pathologist was limited to detecting deviations from the norm, determining the pathological and the normal ${ }^{38}$. The language professional speaks again from a pedagogical position, where their social, historical and ideological position is determined by their history, preventing them from being considered the absolute origin of their own speech ${ }^{36}$.

In this context, it was found that ideological narcissism tries to prevent this professional from contacting the true side of the clinic when speech is lacking, resulting in an idea of debt and charge in the unconscious of therapists. Then, in the development of their speech, they return again to the hierarchical status of speech, resisting and talking about themselves through the voice of others: "this happens due to our culture: Oh! The child must speak, he is too lazy to speak, let's force him to speak, right...? The speechlanguage pathologist works with communication and not necessarily speech... they want to speak, which is the final objective and there is a very strong demand" (excerpt from the interview of S8); "And then, after the work, as a prognosis, which is provided by speechlanguage pathology, the family still is demanding... Oh! Ok, but when is he going to speak?" (excerpt from the interview of S9).

Returning to the initial question: "Are we anchored in correcting speech sounds?". This study shows that this professional also resists through the power by saying "no" to the existing ideological and historical hierarchy. 
Thus, a changing process was found, in which proposing a reflection on the gesture also made it possible to open space for the speech-language pathologists themselves to listen to themselves and find their place to say, resisting ideology and expanding their field of vision: "In this qualification, we prioritize... hum... the rescue of them seeing the child as a whole... with my experience, I saw how much we must see the individual as a whole, right? Not only in pieces, and not only in our area, but how much this individual is involved by the family, world, society, culture, regionalism, by everything" (excerpt from the interview of S10); "Social interactions are crucial for us to be able to establish in that culture, at that moment, what is symbolically important or not... even in a micro or macro context" (excerpt from the interview of S9); "We need to understand this communication, and if we are only demanding to speak, the person ends up discouraged" (excerpt from the interview of S8).

With respect to the expression "speaking with the hand", used by many therapists: "I can't speak without my hand" (excerpt from the interview of S11); "I'm always talking with my hand, even to talk on the phone" (excerpt from the interview of S5); "I believe it may be related to all speech-language pathologists, it seems that we talk using our hands" (excerpt from the interview of S12) evidenced the opening of other senses to the signifier "speech". As reported by Orlandi, it is not a question of modifying the signifier "Speech-Language Pathology", as "speaking with the hands" indicates the real multiplicity of forms that the subjects have to produce meanings ${ }^{33}$. Furthermore, it shows that the sliding of meanings of this signifier has been moving away from the idea of phonation and articulation of sounds, towards what affects the other through its effects of senses. In this way, it is possible to notice the transformation that the DA shows, since something that was done unconsciously "Actually, I don't think about it much when I'm in my clinical practice" (excerpt from the interview of S6); "We end up doing it unconsciously due to our training" (excerpt from the interview of S6); seems to be being questioned, displacing established beliefs and promoting effects of different meanings.

The Discourse Analysis methodology also evidences a discourse that questions the ideology and authoritarianism of the language that defines the identity of the speech-language pathologist, as Fono-audió-logo, allowing the redefinition of the professional and the discursive object in question: "No, I never really thought of that, right? Now that you came up with these questions, we see how much this is part of our clinical context, and that the communication we know is not just speech, it is a whole" (excerpt from the interview of S5); "Now, I'm very curious, thank you for that, I believe this is not a contribution, I believe it is a learning experience. Now, I'm leaving here and I'm heading home to start researching and understanding and I will want to read your study later. So, please send this study to me, as I want to study and learn, right?" (excerpt from the interview of S9).

Transformation then moves to a macro view that questions fragmentation and aims to reconstruct the pieces of the subjects and also of Speech-Language Pathology, enabling new meanings to this signifier.

\section{DISCUSSION}

The use of gestures as objects of discourse by the speech-language pathologist is included in this study as the challenge of a narcissistic gap in the speech-language pathology clinic. This is a gap that resists being analyzed, but that eventually returns as a symptom, shaking structures that are consolidated by history, ideology and the positivism of science.

Broadening the focus of vision to look at the gesture implied showing the guiding thread of the discourse of the speech-language pathologist in the plot of meanings constructed throughout its history and that, for an ideological and hierarchical issue, insists at all times on the return to speech for the elaboration of its saying. This does not mean that the contradictory is not questioned. This study shows that there is a process in transformation in the discourse about the gesture, allowing the reconstruction of what had been fragmented and opening spaces for the mobilization of previously crystallized meanings, such as, the very idea of speech and, consequently, the identification of the speech-language pathologist.

The use of therapeutic approaches described in the literature, such as the SUVAG method and Gesture Prompting were confirmed as part of the practice of these professionals. The use of gestures as management was also showed in a unique way to each therapist in the fields of speech, voice, writing and auditory rehabilitation, which implies that many of the therapeutic approaches have been built on a daily basis as a need for action.

This study shows that a value judgment is attributed to the gesture, especially for therapists who work with subjects who lack speech. This means that gestures 
are used as an important tool for those subjects who have no orality.

Furthermore, the analysis of the discourse through the effect of the meanings of the gestures and the materialistic methodological theory also made it possible to bring to light their connection in the course of words, indicating the possibility of this analysis. Thus, non-verbal elements are also part of the conditions to produce a discourse, showing that there is a need for a theory of gesture as a symbolic act of the theory of the signifier that would contribute greatly to the resolution of many problems in the field ${ }^{39}$. Thus, in addition to contributing to the speech-language pathology clinic and to the reflection on the object of science of Speech-Language Pathology, this study instigates and proposes to the DA to go beyond what is included in the discourse only by words, accepting the risk of not reducing it only to language, but through the course of movements of what is not verbalized ${ }^{40}$.

Finally, although little mention in the scientific context, it is worth mentioning that the gesture in the speech-language pathology clinic highlights the importance of alerting all the senses of the speech-language pathologist to not only listening to words, but also looking and all possible senses, in order to be able to read the other in all its details. In addition, it is extremely important that the speech and analysis of this valuable cursor of meanings is better included in the knowledge of this professional.

\section{CONCLUSION}

Researching the gesture in speech-language pathology clinic from the perspective of the Materialist Discourse Analysis made it possible to highlight the influence of history, ideology in science and social relations in the materiality of the language in the discourse of the speech-language pathologist. This study made it possible to shake the structures of what is consolidated by the threat of beliefs, bringing the gesture to light to possibly include it more and more in the speech-language pathology clinic as an important research object and instrument of evaluation, diagnosis and therapeutic practice.

\section{REFERENCES}

1. Freire R. Se Silêncio, que Silêncio: em cena a clínica fonoaudiológica. Distúrb. Comum. 2009;1(21):101-05.
2. Nunes LROP. Linguagem e Comunicação Alternativa: uma introdução. In: Nunes LROP (org). Favorecendo o Desenvolvimento da Comunicação em Crianças e Jovens com Necessidades Especiais Educacionais. Rio de Janeiro: Dunya; 2003. p.1-13.

3. Chun RYS. Comunicação suplementar e/ou alternativa: abrangência e peculiaridades dos termos e conceitos em uso no Brasil. Pró-Fono $\mathrm{R}$ Atual Cient. 2009;1 (21):69-74.

4. Fedosse E, Santana AP. Gesto e Fala: ruptura ou continuidade? Distúrb. Comum. 2002;2(13):243-55.

5. McNeill D. Language and Gesture. UK: Cambridge University Press; 2000.

6. McNeill D. Hand and mind: what gestures reveal about thought. USA: Chicago University Press; 1992.

7. Iverson J, Goldin-Meadow S. Gestures paves the way for language development. Psychol Sci. 2005;16(05):367-71.

8. Kendon A. Gestures as illocutionary and discourse structure markers in southern Italian conversation. J Pragmat. 1995;23(3):247-79.

9. Capone NC, Mcgregor KK. Gesture development: a review for clinical and research practices. J Speech Lang Hear R. 2004;47(1):173-86.

10. Yu C, Smith LB. Multiple sensory-motor pathways lead to coordinated visual attention. Cogn Sci. 2016;1(21):5-31.

11. Goldin-Meadow SG, Alibali MW. Gesture's role in speaking, learning, and creating language. Annual Rev Psychol. 2013;64(1):257-83.

12. Guedes ZCF. A Linguagem por meio dos gestos. In: Kyrillos LV (ed). Expressividade: da Teoria à Prática. Revinter, Rio de Janeiro; 2005. p. 75-89.

13. Rauscher FH, Krauss RM, Chen Y. Gesture, speech, and lexical access: the role of lexical movements in speech production. Psychol Sci. 1996;7(4):226-31.

14. Cook SW, Goldin-Meadow S. The role of gesture in learning: do children use their hands to change their minds? Cogn Develop. 2006;7(2):211-32.

15. Fedosse E. Da relação linguagem e praxia: estudo neurolinguístico de um caso de afasia [dissertação]. Campinas (SP): Universidade Estadual de Campinas, Instituto de Estudos da Linguagem; 2000.

16. Code $C$, Gaunt C. Treating severe speech and limb apraxia in a case of aphasia. Int $\mathrm{J}$ Lang Comm Dis. 1986;21(1):11-20.

17. Coudry MIH. Língua, discurso e lógica da linguagem patológica. Cadernos da FFC. 1977;6(2):99-129. 
18. Losápio MF, Pondé MP. Tradução para o Português da Escala M-CHAT para Rastreamento Precoce de Autismo. Rev Psiquiat. 2008;30(3):221-9.

19. Muratori F. O Diagnóstico precoce no Autismo: guia prático para pediatras. Núcleo Interdisciplinar de Intervenção Precoce da Bahia, Salvador; 2014.

20. Barbosa MA, Oliveira MA, Siqueira KM, Damas KCA, Prado MA. Linguagem Brasileira de Sinais: um desafio para a assistência de enfermagem. Rev Enferm UERJ. 2003;7(3):247-51.

21. Sheetz NA. Orientation to deafness (2 ed). Allyn and Bacon, Needham Heights, Massachusetts; 2001.

22. Guarinello AC, Massi G, Berberian AP, Tonocchi $R$, Lustosa SS. Speech language therapy bilingual clinic, a written language therapeutical proposal to deaf people: case report. CoDAS. 2015;27(5):498-504.

23. Pelosi MB. Proposta de implementação da comunicação alternativa e ampliada nos hospitais do município do Rio de Janeiro. Temas Desenvol. 2005;14(80-81):47-53.

24. Pelosi MBA. Comunicação alternativa escrita. In: Nunes LROP (ed). Favorecendo o desenvolvimento da comunicação em crianças e jovens com necessidades educacionais especiais. Dunya, Rio de Janeiro, RJ; 2003. p. 203-16.

25. Leybart J, Lasasso CJ. Cued speech for enhancing speech perception and first language development of children with cochlear implants. Trends Hear. 2010;2(14):96-112.

26. Passy J. A Handful of sounds: cued articulation in practice. Acer Press, Camberwell, Victoria; 2003.

27. Sheeny K, Duffy H. Attitudes to Makaton in the Ages on integration and inclusion. Int $\mathrm{J}$ Spec Educ. 2009;24(02): 91-102.

28. Seal B. About Baby Signing. The ASHA Leader [serial on the internet]. 2010 Nov. Available from: http://leader.pubs.asha.org/article.aspx?articleid= 2291803

29. Tabak J. Significant gestures: a history of American sign language. Westport, Praeger; 2006.

30. Asp CW. Verbotonal Speech Treatment. Plural Publishing, San Diego, CA; 2006.

31. Mattos PLCL. A entrevista não-estruturada como forma de conversação: razões e sugestões para sua análise. RAP. 2005;39(4):823-47.

32. Orlandi EP. Análise de discurso: princípios e procedimentos (2 ed). Pontes, Campinas, São Paulo. 2000.
33. Orlandi EP. Interpretação: autoria, leitura e efeitos do trabalho simbólico. Vozes, Petrópolis, Rio de Janeiro; 1996.

34. Pecheux M. Language, semantics and ideology. St. Martins Press, New York; 1982.

35. Brandão HKN. Introdução à análise do discurso (2 ed). Editora da Unicamp, Campinas, São Paulo; 2004.

36. Lagazzi S. O Desafio de dizer não. Pontes, Campinas, São Paulo; 1988.

37. Pereira LTK, Godoy DMA, Terçariol D. Estudo de caso como procedimento de pesquisa científica: reflexão a partir da clínica fonoaudiológica. Psicol Reflex Criti. 2009;22(3):422-9.

38. Aarão PC, Pereira FCB. Histórico da Fonoaudiologia: relato de alguns estados brasileiros. Rev Med. 2011;21(2):238-44.

39. Pecheux, M. Análise automática do discurso. In: Gadet F, Hak T (eds). Por uma análise automática do discurso: uma introdução a obra de Michel Pecheux. UNICAMP, Campinas, SP; 1993. p. 319.

40. Courtine JJ. Análise do discurso político: o discurso comunista endereçado aos cristãos. EdUFSar, São Carlos, SP; 2014. 